Indexed by

\title{
DESIGN DEVELOPMENT AND TECHNICAL ANALYSIS OF ANAUTO CHECKING HARDNESS MACHINE - A STUDY CASE OF THE HARDNESS TESTER HR-522 SERIES
}

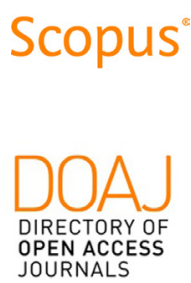

Crossref

\section{Bernardus Plasenta Previo Caesar \\ Universitas Sebelas Maret, De- partment of Mechanical Engi- neering, Surakarta, Indonesia}

\section{Muhammad Faiz Dzulfikar}

Universitas Sebelas Maret, Department of Mechanical Engineering, Surakarta, Indonesia

\section{Aditya Rio Prabowo}

Universitas Sebelas Maret, Department of Mechanical Engineering, Surakarta, Indonesia

\section{Pandu Sandi Pratama}

Dong-A University, Cobot Co., Industry Research Building Room 121, Busan, South Korea

\section{Joung Hyung Cho}

Pukyong National University,

Department of Industrial De-

sign, Busan, South Korea

Key words: auto checking hardness machine, finite element method, aluminum frame design, displacement value, maximum stress, safety factor doi:10.5937/jaes0-29822

Cite article:

Caesar, B. P. P., Dzulfikar, M. F., Prabowo, A. R., Pratama, P. S., Cho, J. H. (2021) DESIGN DEVELOPMENT AND TECHNICAL ANALYSIS OF ANAUTO CHECKING HARDNESS MACHINE - A STUDY CASE OF THE HARDNESS TESTER HR-522 SERIES, Journal of Applied Engineering Science, 19(3), 731-742, DOI:10.5937/jaes0-29822

Online aceess of full paper is available at: www.engineeringscience.rs/browse-issues 


\title{
DESIGN DEVELOPMENT AND TECHNICAL ANALYSIS OF AN AUTO CHECKING HARDNESS MACHINE - A STUDY CASE OF THE HARDNESS TESTER HR-522 SERIES
}

\author{
Bernardus Plasenta Previo Caesar', Muhammad Faiz Dzulfikar', Aditya Rio Prabowo ${ }^{1 *}$, \\ Pandu Sandi Pratama', Joung Hyung $\mathrm{Cho}^{3}$ \\ ${ }^{1}$ Universitas Sebelas Maret, Department of Mechanical Engineering, Surakarta, Indonesia \\ ${ }^{2}$ Dong-A University, Cobot Co., Industry Research Building Room 121, Busan, South Korea \\ ${ }^{3}$ Pukyong National University, Department of Industrial Design, Busan, South Korea
}

\begin{abstract}
A hardness-checking machine is a crucial tool in engineering studies, especially in mechanical and manufacturing processes. It is usually used to measure, calibrate, and standardize the quality of products. This study is based on the field problem in Akebono Brake Astra, Indonesia, where more manual tools are used to meet product demands. In consideration of this issue, a modified hardness checking tool with automatic operation has been developed. Using automatic operation is beneficial in terms of time and cost efficiency in comparison with other manual tools. Automatic tools apply the 3-axis system mechanism, using a Festo linear actuator with a servo motor. The testing capacity of automatic devices is equal to more manual devices. The frame of the auto checking hardness machine is assessed in this study by applying load variations. Drawing on other similar work on auto checking hardness machines, this paper provides a comparison of various aluminum frame types based on different tensile strengths and cross-sectional area values. The baseplate for hardness testing is also calculated. There are 9 testing points for calculating the use of linear guides for the baseplate. The results show excellent tensile strength values, as well as a good displacement and maximum stress.
\end{abstract}

Key words: auto checking hardness machine, finite element method, aluminum frame design, displacement value, maximum stress, safety factor

\section{INTRODUCTION}

Material testing, calibration, and analysis are the essential processes in the material and structural characterizations of materials that are possibly subjected to various loads in technical applications [1-7]. The main material testing variable is hardness, which represents the resistance properties due to deformation and destruction. Deformation includes elastic deformation, plastic deformation, the press-in process, and scratches. Generally, the testing of material hardness includes Rockwell, Brinnel, Vickers, and Micro Hardness. Every test applies a manual non-destruction system that does not inflict damage to the material [8]. New hardness tests that comply with production demands need to be developed, for example, in Akebono Brake Astra, Indonesia, where more manual hardness testers with a single capacity are used. To the academic person or researcher, this indicates the need for the development of new tools. The checking product used in the company represents approximately $10 \%$ of their massive production, and this product must be checked through quality control.

Moreover, manual hardness testers are operated by an operator [9], causing problems associated with bottlenecks, efficiency, cycle times, and human error. This paper provides reverse engineering knowledge to modify the manual hardness check of the Mitutoyo Hardness Tester Hr-522 series, thus producing an Auto Checking Hardness Machine. The Auto Checking Hardness Machine is used as a substitute for manual tools. The auto checking hardness machine applies a 3-axis system mechanism, with a linear drive and a servo motor as the driver.

\section{ENGINEERING DESIGN FOR MODIFIED HARDNESS TESTER}

\section{Design flow}

The study of reverse engineering in this paper studies the sequences of stages of an object's deconstruction or modification to complement its design and provide a new purpose [10]. Reverse engineering studies are not only concerned with creating a copy product or changing the shape of a product [11]. They are based on engineering analysis, which consists of structural analysis, dynamics analysis, and material processes. Figure 1 shows the design flow of our reverse engineering study, involving the design and modification of the Auto Checking Hardness Machine.

This research starts by defining the problem based on a literature review. Chapter 1 shows the investigation of the highlighted issues, while in chapter 2 , a literature review is conducted to explain the existing theory. The design process starts with a creative design and detailed design. The creative design involves a sketch design of the product, the preliminary design involves the 3D modelling of $C A D$, and the detailed design is the result of a simulation process. This paper provides the reverse engineering design flow process up to the detailed design stage. 


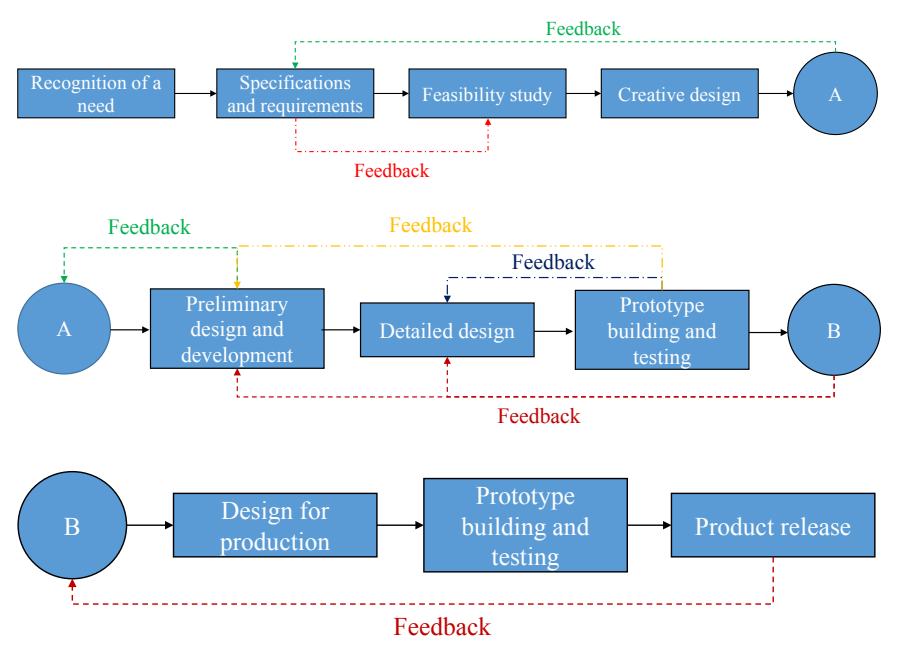

Figure 1: Design flow of reverse engineering process(Re-drawn based on [10])

\section{Design process}

\section{Field study}

Reverse engineering concepts are applied in the actual case of Akebono Brake Astra Indonesia's Quality Check department (see Figure 2). Ideally, a tool is operated by an operator. However, the actual case shows that six tools are operated by an operator. Figure 2 shows the application of 6 Mitutoyo Hardness Tester HR-522 manual tools that are operated by a single operator.

From Figure 2, the problems that need to be solved include the replacement of 6 manual hardness testing machines by one modified hardness testing tool with an automatic system that can replace the testing capacity of 6 manual hardness testing machines. Using the Auto Checking Hardness Machine, manual work is reduced, as the machine works automatically. Therefore, the operator only prepares the test specimen. The standard brake pad hardness test is divided into 4 rectangular points, and the hardness test value of each specimen is automatically inputted into the operator's computer for the process of checking and evaluation. The other automatic machine for hardness testing by TA Instruments, New Castle, United Kingdom is shown in Figure 3 and Table 1 [12].

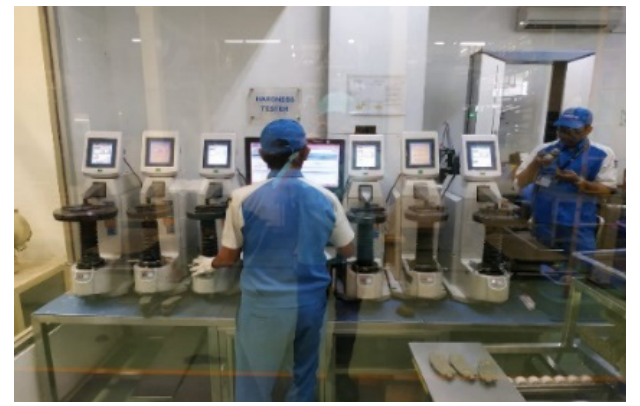

Figure 2: Illustration of an operator conducts hardness test using six tools [9]

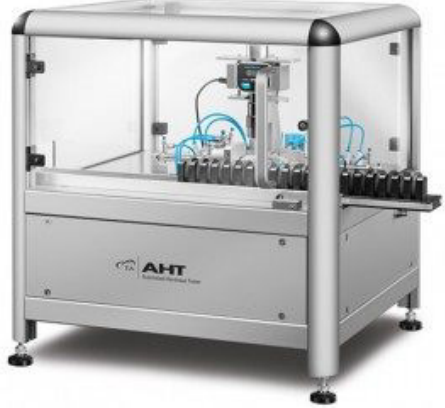

Figure 3: Automated Hardness Tester (AHT) [12]

However, there are some drawbacks of this automatic hardness tester: this tool is not designed to check the shape of brake pads because the dimensions of this tool are $30-45 \mathrm{~mm}$ in diameter, with a thickness $4-6 \mathrm{~mm}$. It therefore requires a bigger space than is available, and it requires a high cost, including maintenance costs. However, manual tools will be unused if they are replaced with an Automated Hardness Tester (AHT).

\section{First concept}

The design process of the Auto Checking Hardness Machine has several stages. The first stage of the design was obtained after studying the needs of the market. Figure 3 denotes the first concept design of the Auto Checking Hardness Machine. It applies a linear actuator for the vertical mechanism and a rotary actuator for the rotating mechanism. Unfortunately, the testing point in this concept forms a curved pattern. Thus, it cannot be used in the quality control due to the testing standard, which requires hardness testing in four rectangular points.

\section{Discussion}

The discussion process includes the decision-making process after the first concepts are defined, which generates three designs (Figure 4). The difference between the 3 optional designs is the position of the 3-axis mechanism linear drive. The first option exhibits the Z-axis (Red), X-axis (Blue), and Z-axis (Green), from the bottom. The second option exhibits the $X$-axis (Blue), $Y$-axis (Green), and Z-axis (Red) position. The third option exhibits the Y-axis (Green), X-axis (Blue), and Z-axis (Red) position. Every linear drive employs a Festo linear drive.

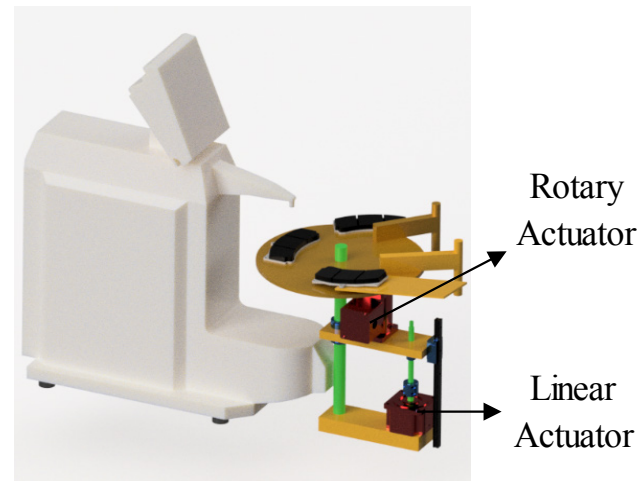

Figure 4: First design concept 


\section{Design modelling}

\section{Concept evaluation}

The difference between the three design concepts lies in the position of each axis. Design 1 gives the bottom-most position to the $\mathrm{Y}$-axis, followed by the $\mathrm{X}$-axis and $\mathrm{Z}$-axis [see Figure 5 (a)]. Design 2 gives the bottom-most position to the $\mathrm{X}$-axis, followed by the $\mathrm{Y}$-axis and $\mathrm{Z}$-axis [see Figure 5 (b)]. Design 3 gives the bottom-most position to the Y-axis, followed by the $X$-axis and Z-axis [see Figure $5 \mathrm{c}$ )]. The criteria included whether it is strong and safe, ergonomic, comfortable to use in manufacturing, easy to maintain, and lightweight, as well as whether it has a minimalist size. Table 1 shows the results of the design evaluation, which indicates that design scenario 3 [Figure 5 (c)] has the best results according to the parameter assessment.

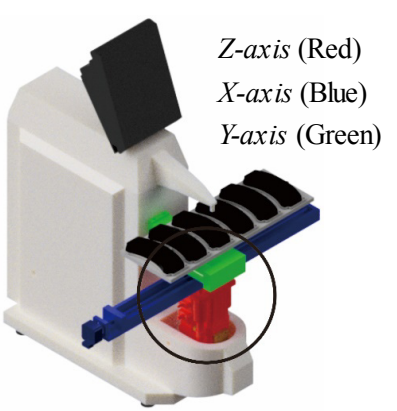

(a)

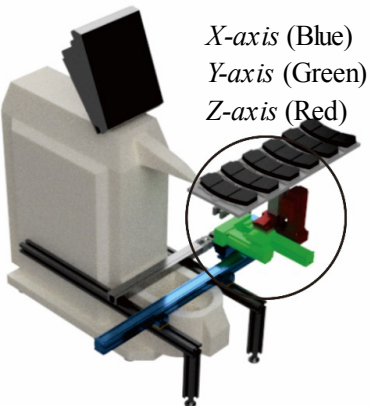

(b)

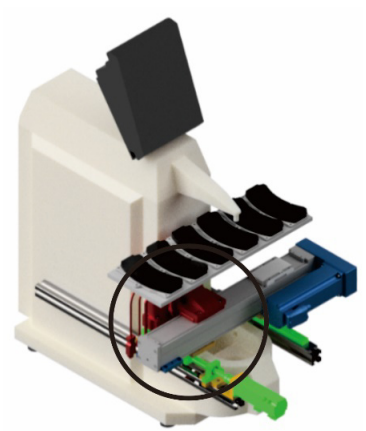

(c)

Figure 5: Optional design of Auto Checking Hardness Machine

\section{Design assembly}

Each design assembly has a linear drive, adapter kit, parallel kit, servo motor, and linear guides [see Figure 6]. The adapter kit plays an essential role in connecting every linear drive into the frame [13]. The parallel kit connects the linear drive with the servo motor in a parallel position, and the linear guides brace the loads and assist the linear drive movements. An EGSC linear drive is used on the Z-axis to withstand vertical loads. A $600 \mathrm{~mm}$ Festo ELGC linear drive is used on the $X$-axis to fill-up the most significant brake pad width. A $100 \mathrm{~mm}$ Festo ELGC linear drive and Festo ELFC linear guides are used on the Y-axis to fill-up the most significant brake pad length.

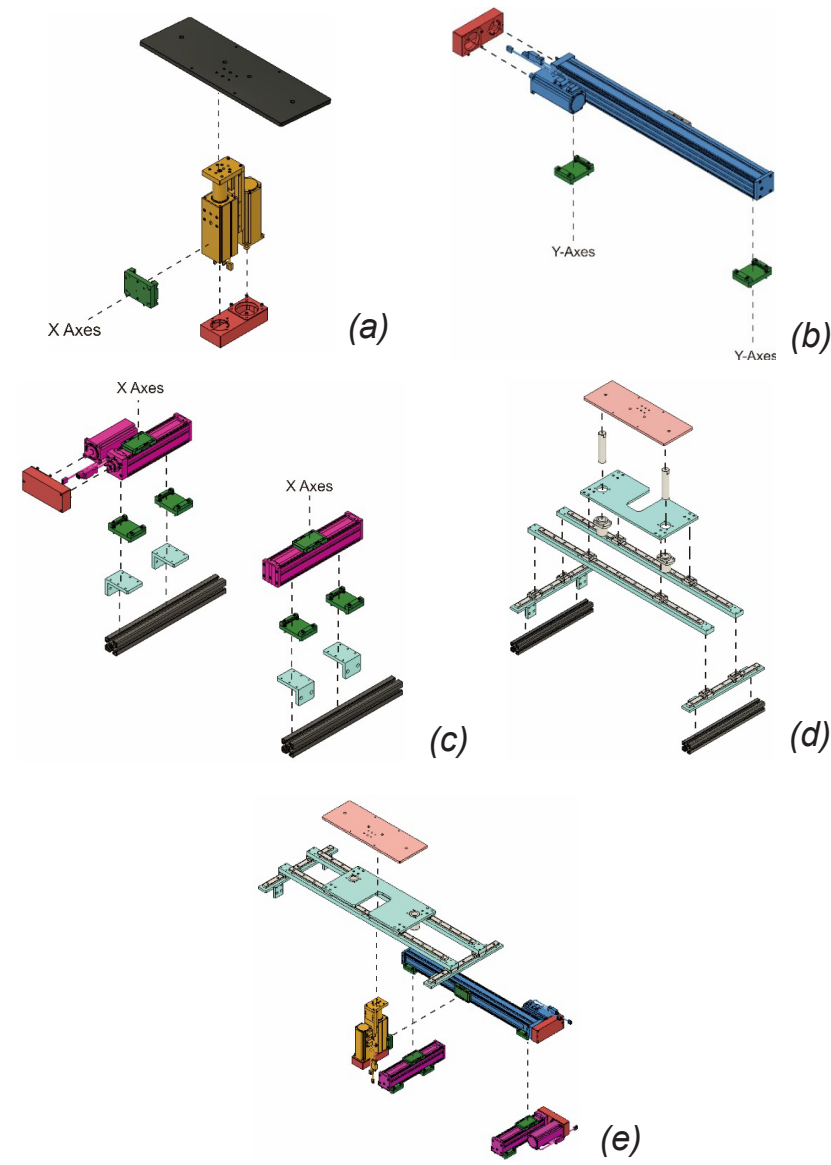

Figure 6: Components of design assembly

Table 1: Design evaluation matrix of Auto Checking Hardness Machine

\begin{tabular}{|c|c|c|c|c|c|c|c|c|c|}
\hline \multirow{3}{*}{ Parameter } & \multirow{3}{*}{ Value } & \multicolumn{8}{|c|}{ Design concept } \\
\hline & & \multicolumn{2}{|c|}{ Scenario 1} & \multicolumn{2}{|c|}{ Scenario 2} & \multicolumn{2}{|c|}{ Scenario 3} & \multicolumn{2}{|c|}{ Maximum reference } \\
\hline & & Score & $\begin{array}{l}\text { Score } \\
\text { value }\end{array}$ & Score & $\begin{array}{l}\text { Score } \\
\text { value }\end{array}$ & Score & $\begin{array}{l}\text { Score } \\
\text { value }\end{array}$ & Score & $\begin{array}{l}\text { Score } \\
\text { value }\end{array}$ \\
\hline Strength and safety & $20 \%$ & 3 & 0.6 & 4 & 0.8 & 5 & 1 & 5 & 1 \\
\hline Ergonomic & $20 \%$ & 2 & 0.6 & 3 & 0.6 & 3 & 0.6 & 5 & 1 \\
\hline Manufacturability & $20 \%$ & 2 & 0.4 & 3 & 0.6 & 4 & 0.8 & 5 & 1 \\
\hline Minimalistic & $20 \%$ & 4 & 0.8 & 3 & 0.6 & 3 & 0.6 & 5 & 1 \\
\hline Easy maintenance & $10 \%$ & 3 & 0.3 & 3 & 0.3 & 3 & 0.3 & 5 & 0.5 \\
\hline Weight & $10 \%$ & 3 & 0.3 & 4 & 0.4 & 3 & 0.3 & 5 & 0.5 \\
\hline Total & & & 3 & & 3.3 & & 3.6 & & 5 \\
\hline
\end{tabular}




\section{Component detail}

The components used are linear drives, linear guides, and Keyence security sensors. This security sensor is used to keep the operator safe during the testing process [14]. The linear guides used are Misumi LGR SE2B-400 at $400 \mathrm{~mm}$ [see Figure 6 (d)]. The Auto Checking Hardness Machine was supported by a $45 \times 45 \mathrm{~mm}$ aluminum frame, with an additional $2 \mathrm{~mm}$ metal frame cover (see Figure 7).

\section{ANALYSIS PREPARATION}

\section{Finite element benchmarking}

\section{Design and configuration}

The validation process is a method used to prove that a research methodology can be valid [15]. The validation process in this research complies with the design research and static analysis of the Shell Eco-Marathon frame concept chassis analyzed in our previous work, published in [16], on finite element simulation, which will be used for comparison under the same boundary condition. This paper provides a comparison of manual calculation, the Autodesk Inventor simulation used in previous works, and the current work using Autodesk Fusion 360. This preliminary design was developed using the

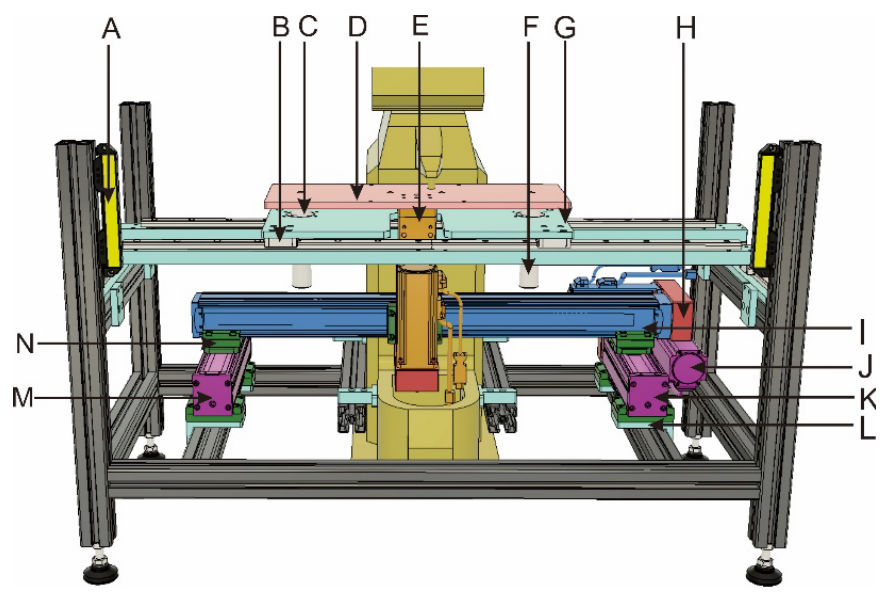

A: Safety Sensor Keyence

B: Misumi LGR SE2B - 400

C: Linear Bushing Base

D: Brake Pad Jig Base

E: Festo EGSC - BS - KF - 60 - 75 12P

F: Misumi Linear Bushing MFINS30

G: Linear Guide Base

$\mathrm{H}$ : Festo Parallel Kit-EAMM-U-65-T42

I: Festo Linear Drive ELGC-BS-KF-60

$\mathrm{J}$ : Festo Motor - EMMB - AS - 60 - 02

K: Festo Linear Drive ELGC - BS - KF

$\mathrm{L}$ : Mounting to Frame

M: Festo Linear Guide ELFC - KF - 60

$\mathrm{N}$ : Festo Adapter Kit EHAA - D - L2

Figure 7: Detailed component assembly
Autodesk Inventor [9]. This research uses ladder frame type chassis, with aluminum square hollow type AA 6061 as the main material. The dimensions are 2060mm long and $600 \mathrm{~mm}$ wide, with two main aluminum bars $(40 x 40 \mathrm{x}-$ $2 \mathrm{~mm}$ ), and the structure is reinforced by seven aluminum supporting rods $(25 \times 25 \times 3 \mathrm{~mm})[2,9]$. The boundary condition process of Hidayat's research involves the external load on seven aluminum support bars, and the two main aluminum bars are the constraints on this design. The machine's support beam chassis are loaded with $196.2 \mathrm{~N}$ from machine mass and supported by two support beams. The driver's body is loaded with approximately $294.3 \mathrm{~N}$ from the body mass and supported by two support beams. The support beam near the driver's leg is loaded with $98.1 \mathrm{~N}$, as the assumed mass of the driver's leg.

\section{Results}

The parameters used in this research are the maximum stress (MPa), displacement ( $\mathrm{mm})$, and safety factor. The results for the first benchmark show that the highest gap in the simulations is $24.337 \%$, and the lowest gap is $0 \%$ (exactly the same as the benchmark reference). Meanwhile, the comparison of manual calculations and simulations shows a relatively distant difference of up to $43.18 \%$. The average comparison with the smallest manual calculations in the displacement parameter is $56.82 \%$, which is quite striking. The average simulation comparison shows that the validation value is in the range of $0 \%$ to $15.17 \%$.

The second benchmark method used is to vary the mesh size [17-21] from 5 to $60 \mathrm{~mm}$ within an interval of 5 . The mesh size variation is applied within the driver's leg frame area. The driver's leg area is chosen, because the comparison of manual calculation and simulation shows the most significant ratio, compared to other parts of the frame. The parameters affected by differences in mesh size are nodes, elements, maximum stress results, and displacement. Nodes are points that form a smaller geometric shape, which will be analyzed to form elements [22]. The results are summarized in Figures 8 to 10.

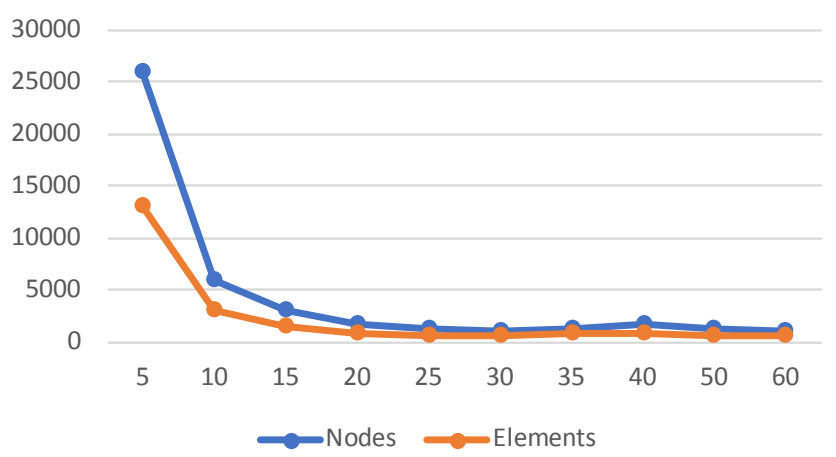

Figure 8: Mesh size benchmark over nodes and elements 


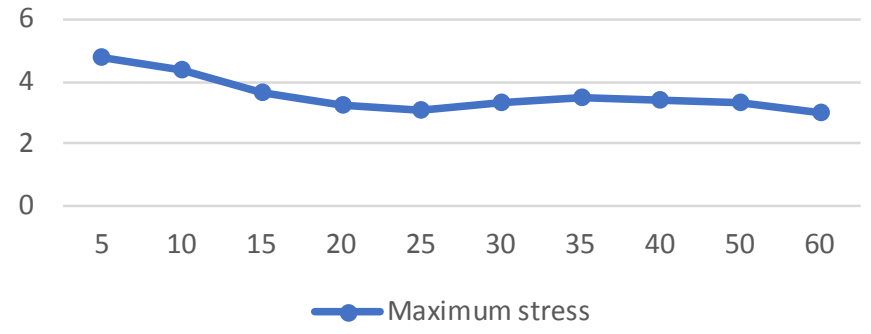

Figure 9: Mesh size benchmark over maximum stress

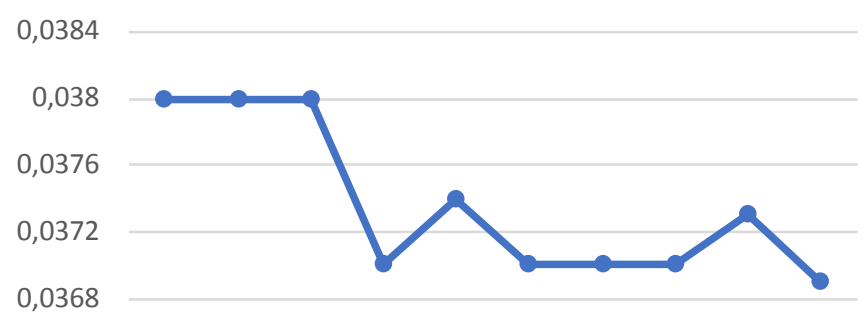

0,0364

0,036

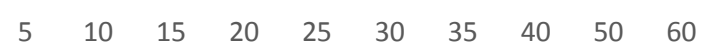

Displacement

Figure 10: Mesh size benchmark over displacement

\section{Extended study on engineering design}

\section{Design and configuration}

The structure design process is adapted to the dimension of a 3-axis motion machine. The dimensions of the frame are determined by the length of the $\mathrm{X}$-axis linear actuator and the length of the Y-axis linear actuator. The Y-axis frames are supported by an additional structure on sections $B$ and $C$ (see Figure 11).

The side frame structure of the Auto Checking Hardness Machine (see Figure 12) is made higher than the main testing machine, with the aim of installing a security sensor. The special bolts are used to connect each aluminum profile of the mainframe. The Mitutoyo Hardness Tester HR-522 testing machine is not directly placed by the frame, because the level of the adjuster and the machine itself is aligned and configured so that the working desk directly supports it (see the mass list in Table 2). The frame meshing has 1,745,598 nodes and 875,321 elements, which also shows four critical points. The

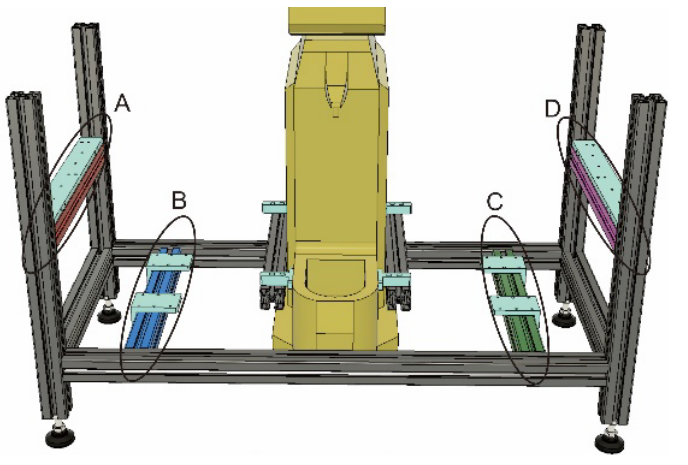

Figure 11: Mesh size benchmark over displacement

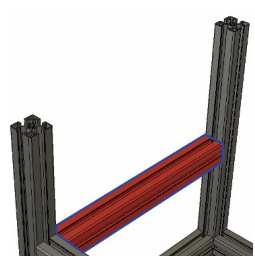

(a)

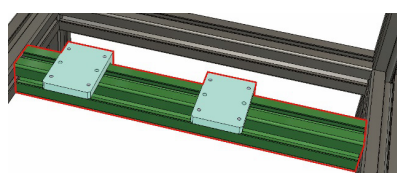

(c)

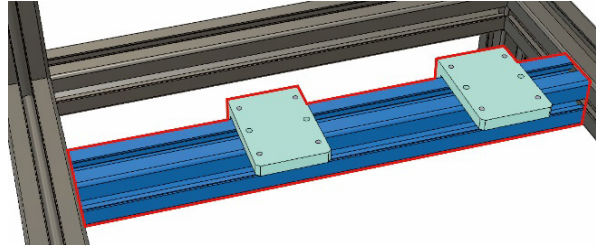

(b)

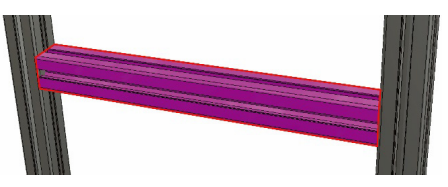

(d)
Figure 12: Meshing uses in the simulation of the frame

frame meshing has a parabolic element order, maximal turn angle on curve of $60^{\circ}$, maximal adjacent mesh ratio of 1.4, and maximal aspect ratio of 1.0. The structural analysis uses Autodesk Fusion 360 to conduct the finite element calculation. The material used for the structure is aluminum profile 6060 series. As presented in Figure 13 , there are six constraints or load points, and four load points are at the bottom of the level adjuster, which is supported on the working table, and two load points are supported by the hardness test machine. In this simulation analysis, the loads are divided into two main types: the 4-point concentrated load and the distributed load on the bottom of the frame. The only constant load is the load on the topside, which supports the linear guides.

The frame of the distributed load scenario (Figure 14) is loaded with a $259.7 \mathrm{~N}$ distributed load. Afterwards, the load is divided into two lower frame arms, where each frame receives a load of $129.85 \mathrm{~N}$. Secondly, the concentrated load scenario is loaded with $259.7 \mathrm{~N}$. It is divided into four mounting frames, making a centered load of $64.925 \mathrm{~N}$. The first and second load scenario have the same distributed loads on the topside frame arms. A load of $380.89 \mathrm{~N}$ is divided across two arms, such that each arm receives a load of $190.445 \mathrm{~N}$.

Table 2: Defined mass of the frame components

\begin{tabular}{|c|c|c|c|c|c|}
\hline No & Part & Mass (kg) & No & Part & Mass (kg) \\
\hline 1 & $\begin{array}{c}\text { Brake } \\
\text { pads }\end{array}$ & 2 & 8 & $\begin{array}{c}\text { Servo } \\
\text { motor }\end{array}$ & 1.6 \\
\hline 2 & $\begin{array}{c}\text { Base } \\
\text { plate }\end{array}$ & 6 & 9 & Parallel kit & 0.6 \\
\hline 3 & Jig & 2 & 10 & Adapter kit & 0.2 \\
\hline 4 & $\begin{array}{c}\text { EGSC } \\
(\mathrm{Z})\end{array}$ & 3.1 & 11 & $\begin{array}{c}\text { Linear } \\
\text { guides (Y) }\end{array}$ & 4.8 \\
\hline 5 & $\begin{array}{c}\text { ELGC } \\
(\mathrm{X})\end{array}$ & 7.9 & 12 & $\begin{array}{c}\text { Linear } \\
\text { guides (X) }\end{array}$ & 17.52 \\
\hline 6 & $\begin{array}{c}\text { ELGC } \\
(\mathrm{Y})\end{array}$ & 2.7 & 13 & $\begin{array}{c}\text { Linear } \\
\text { guides (Z) }\end{array}$ & 2.66 \\
\hline 7 & $\begin{array}{c}\text { ELFC } \\
(\mathrm{Y})\end{array}$ & 2.2 & 14 & $\begin{array}{c}\text { Linear } \\
\text { bushing } \\
\text { base }\end{array}$ & 6.5 \\
\hline
\end{tabular}




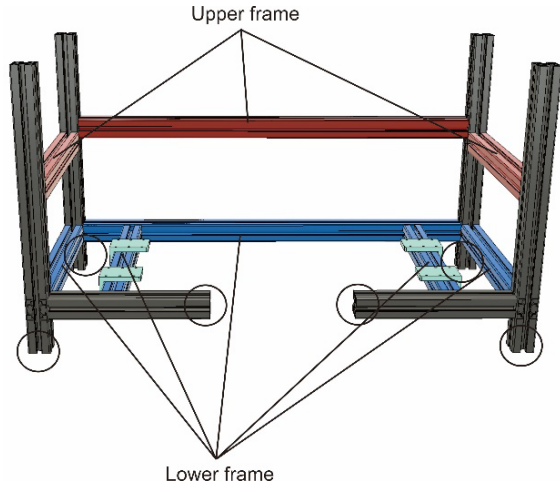

Figure 13: Location of the defined constraint system

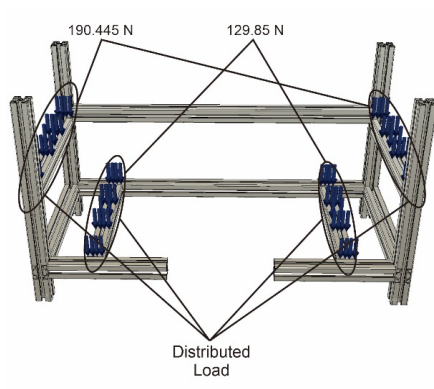

(a)

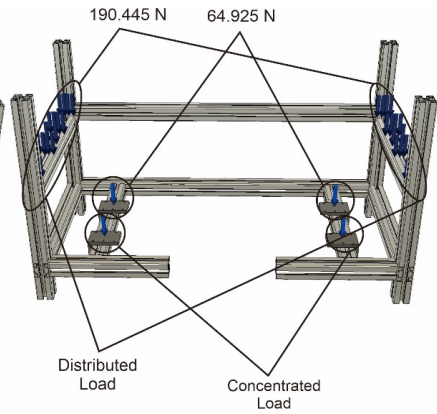

(b)
Figure 14: (a) Distributed load modelling,

(b) Concentrated load modelling

\section{Design and configuration}

Four varieties of aluminum frames can be used in this project: high rigidity, economic, lightweight, and standard aluminum (see Figure 15). These aluminum types are different from the cross-section area and its material properties, as presented in Table 3.

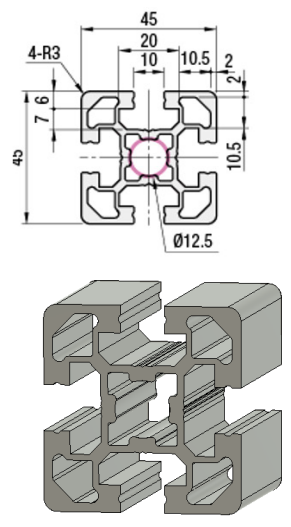

(a)
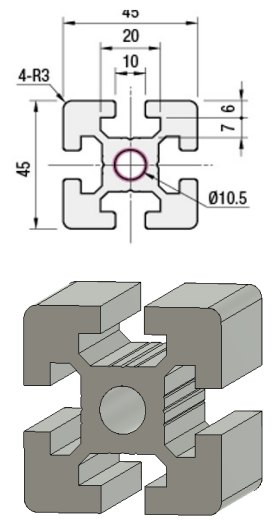

(b)

\section{Setting and configuration for baseplate analysis}

The baseplate is the supporting plate, where the brake pads are situated for the press test. The baseplate is connected to three shafts, including the Festo EGSC linear drive, and supported by the Misumi shaft on the Z-axis. The movement of the Misumi shaft is guided by the Misumi linear bushing, which is placed on the linear bushing base (see Figure 16).

The baseplate is simulated using a static simulation on Autodesk Fusion 360, which also involves the Misumi shaft, baseplate, and yoke plate (Festo EGSC axis Z) [23]. The material used for the baseplate is S45C. The material used for the Misumi shaft is 52100 . The Yoke plate is part of the Z-axis Festo EGSC, which is directly related to the baseplate. The Yoke plate uses aluminum standard material and centered loading, caused by an indenter with a Rockwell S measurement scale of 100KGF. There are nine loading points, but only 6 points are considered as critical points, which are the points in the corner and beside the plate [see Figure 17]. Indenter scale $\mathrm{S}$ is represented with a $12.7 \mathrm{~mm}$ cylindrical body.

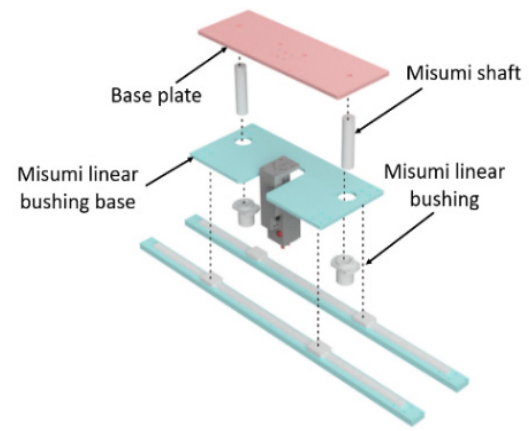

Figure 16: Base plate assembly: 3D illustration
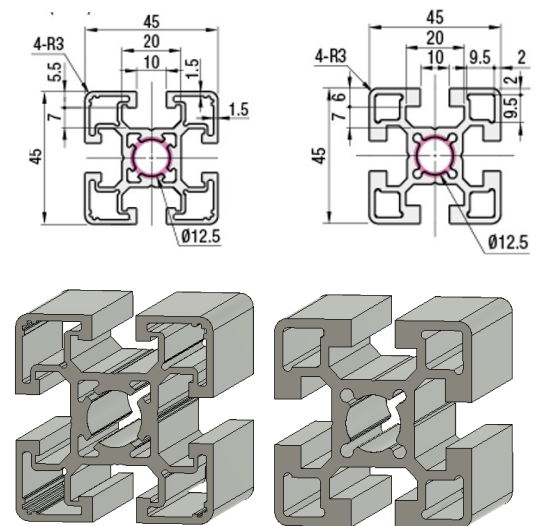

(c)

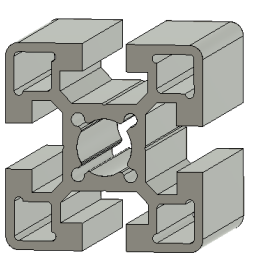

(d)

Figure 15: (a) Economy type, (b) High-rigidity type, (c) Lightweight type, (d) Standard type

Table 3: Properties of material used for the finite element simulation

\begin{tabular}{|c|c|c|c|c|}
\hline Frame type & Aluminum type & Cross Sectional-area $\left(\mathrm{mm}^{2}\right)$ & Tensile strength $(\mathrm{MPa})$ & Material uses on Autodesk Fusion 360 \\
\hline High-rigidity & Al6063S-T6 & 1171 & 330 & Al6060 \\
\hline Lightweight & A6N01SS-T5 & 713 & 265 & Al5052-H34 \\
\hline Economy & A6063S-T5 & 713 & 155 & Al3105-H12 \\
\hline Standart & A6N01SS-T5 & 777 & 245 & Al3004-H34 \\
\hline
\end{tabular}




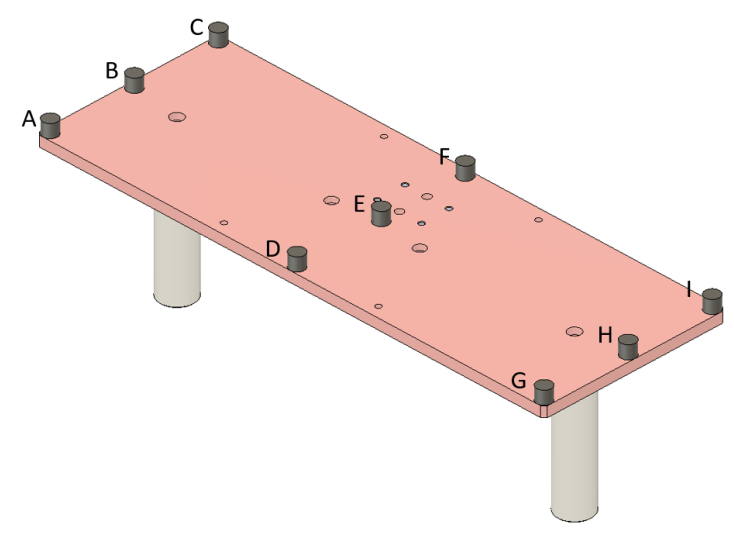

Figure 17: 9 pints loading over the baseplate

There are two types of constraints on the baseplate analysis. The first is the three mounting frames. There are two Misumi shafts and a yoke plate Festo EGSC on the Z-axis. The second is that there is only one mounting point, namely, the yoke plate Festo EGSC on the Z-axis. The constrained placement variety explains the impact of the linear guide in supporting the baseplate [see Figure 18].

\section{RESULTS AND DISCUSSION}

\section{Performance of structural frame}

Static simulations are implemented on a high rigidity-type frame, standard-type frame, lightweight-type frame, and economical-type frame. The simulation conducted using a concentrated load is performed on the lower frame with a supporting 3-axis tool, while in the upper frame, it is performed on the supporting linear guides. Six constraint points work on the frame, the workbench supports 4 points, and 2 points are supported by the Mitutoyo Hardness Tester HR-522. The results of the simulation are explained in Tables 4 and 5.

The distributed load simulation, which has been conducted, has a higher value than the concentrated load due to the lower frame supporting a higher load [24]. This is because the distributed loads are heavier than the concentrated loads. The load received under the framework is $129.85 \mathrm{~N}$. While the load held by the lower frame, with the concentrated load type, is the total load divided by

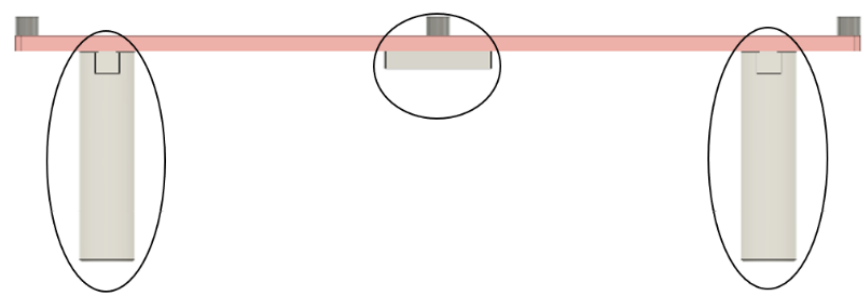

(a)

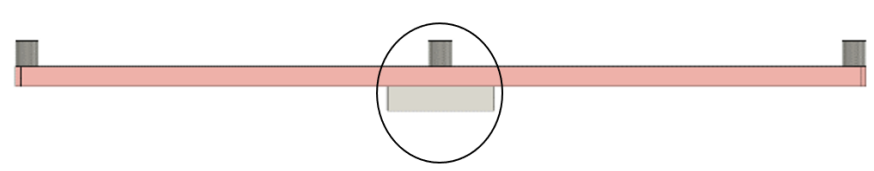

(b)

Figure 18: Baseplate's constraint scenarios
Table 4: FEM static simulation result using distributed load

\begin{tabular}{|c|c|c|c|c|}
\hline Parameter & High-rigidity & Lightweight & Standard & Economy \\
\hline $\begin{array}{c}\text { Displace- } \\
\text { ment } \\
(\mathrm{mm})\end{array}$ & $1.53 \times 10^{-2}$ & $5.23 \times 10^{-2}$ & $5.33 \times 10^{-2}$ & $5.34 \times 10^{-2}$ \\
\hline $\begin{array}{c}\text { Maximum } \\
\text { Tensile } \\
\text { Strength } \\
\text { (MPa) }\end{array}$ & 2.77 & 9.43 & 9.42 & 9.46 \\
\hline $\begin{array}{c}\text { Safety } \\
\text { factor }\end{array}$ & 15 & 15 & 15 & 15 \\
\hline
\end{tabular}

Table 5: FEM static simulation result using concentrated load

\begin{tabular}{|c|c|c|c|c|}
\hline Parameter & High-rigidity & Lightweight & Standard & Economy \\
\hline $\begin{array}{c}\text { Displace- } \\
\text { ment } \\
(\mathrm{mm})\end{array}$ & $8.8 \times 10^{-3}$ & $1.93 \times 10^{-2}$ & $1.97 \times 10^{-2}$ & $1.98 \times 10^{-2}$ \\
\hline $\begin{array}{c}\text { Maximum } \\
\text { Tensile } \\
\text { Strength } \\
\text { (MPa) }\end{array}$ & 2.6 & 5.66 & 5.54 & 5.55 \\
\hline $\begin{array}{c}\text { Safety } \\
\text { factor }\end{array}$ & 15 & 15 & 15 & 15 \\
\hline
\end{tabular}

four 3-axis tool holders, which is $64.925 \mathrm{~N}$. The high-rigidity type, shown in Tables 8 and 9, has the best value compared with the other types. This is because of the properties of the high-rigidity frame type, with a cross-sectional area and tensile stress. The lightweight, standard, and economic type generate almost the same value. The economic type has a weak value, because it has the most significant result in all parameters. This is because the economic-type frame has the smallest value for all other properties, besides the tensile strength and cross-sectional area [25]. The maximum stress on the lightweight aluminum frame in the concentrated load simulation is higher than that on the standard and economic-type aluminum frames. Conversely, in the distributed load, the maximum stress on the lightweight aluminum frame is higher than that of the standard-type aluminum frame. This phenomenon may be because the maximum stress value is determined by the cross-sectional area, which affects the moment of inertia. While the cross-sectional area of the lightweight-type frame and the economic-type frame are the same, the tensile strength of the two frames is very different, at $110 \mathrm{MPa}$. This makes the maximum stress value of the lightweight-type frame lower than that of the economy-type frame in uniform loading [26].

In both static tests of the distributed load and concentrated load (Figures 19 and 20), the displacement values for the high rigidity-type are the highest, followed by the lightweight-, standard-, and economic-type aluminum frames. 


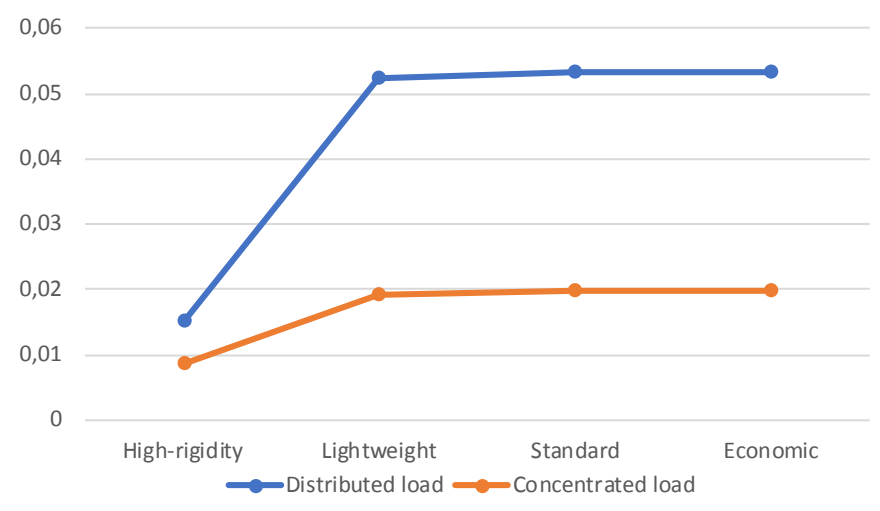

Figure 19: Comparison of displacement values on distributed and concentrated loading

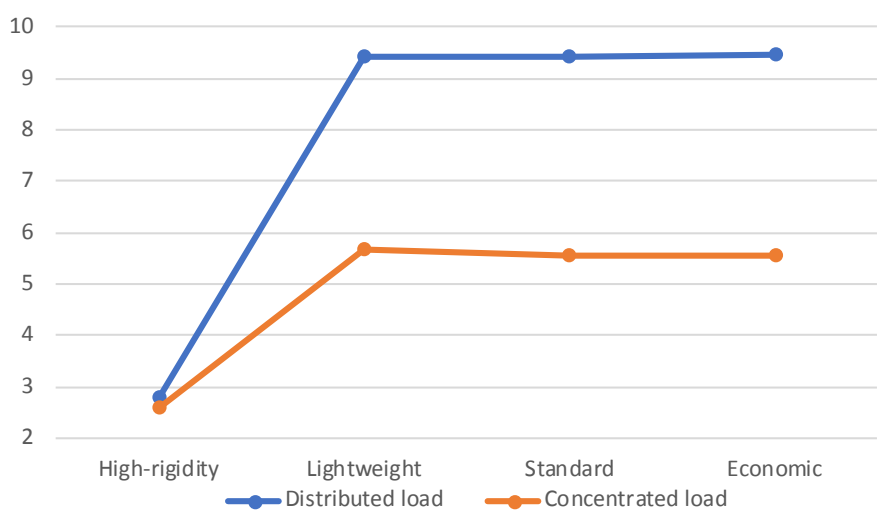

Figure 20: Comparison of maximum stress values on distributed and concentrated loading

This is consistent with the distribution of the material's tensile strength properties, indicating that the higher the tensile strength value of a material, the lower the displacement value and that the material can withstand a load through deflection [27]. The following explanation can be seen from the three parts of the frame that have the most critical reactions (Figures 21 and 22). The displacement simulation involves the frame of the distributed load area in part A, the lower frame in parts $B$ and $\mathrm{C}$, and the frame that connects it. The stress simulation involves the upper frame of the distributed load area in part $A$, the lower frame in part $B$, and the connection of the frame in part $\mathrm{C}$.

From Figures 21 and 22, it can be seen that there is a difference between the 2 static structural simulations in terms of load variations. In the distributed load area of
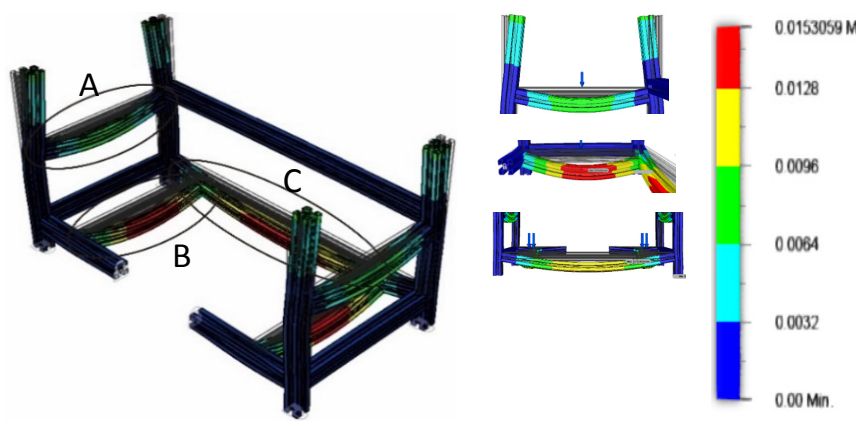

Figure 21: Structural analysis: displacement contour of distributed loads high-rigidity type frame
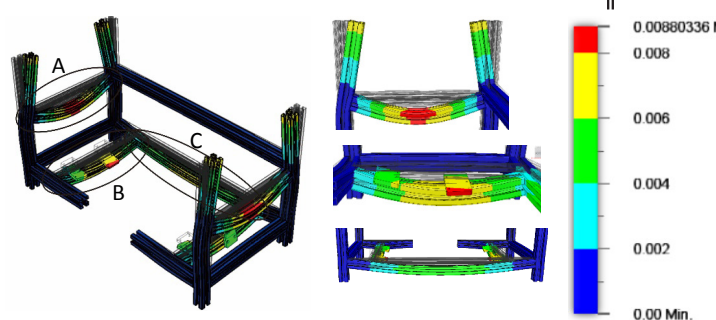

Figure 22: Structural analysis: displacement contour of concentrated loads high-rigidity type frame

Part $B$, there is more deformation (shown in red). This is because the load of the distributed variation in Part $B$ is divided into two frames. In contrast, the load of the concentrated variation in Part $B$ is divided into four mounting frames. The green color in the middle of Part A (distributed load) has more deflection $(\mathrm{mm})$ than the red in the concentrated load area, as reviewed by a color range on the right side. The distributed load in Part A produces $0.0096 \mathrm{~mm}$ (green color), while the concentrated load in Part A produces $0.0088 \mathrm{~mm}$ (red color).

\section{Performance of the baseplate}

The analysis of the 9-point baseplate simulation, showing the six most critical points, is shown in Table 6 and Figures 23 to 25 . The aim was to predict the reaction of the baseplate in the testing process and the loading of the indenter, because the baseplate is the first part that holds the load of the indenter [28]. The parameters generated from this simulation are displacement, maximum stress, and safety factors [29-34]. The displacement value in design 1 and design 2 has points with the same upward and downward trends. The maximum stress value is also similar to the displacement value, because design 1 produces a better value than design 2 at six critical points (A, B, C, G, H, and I). The difference chart shows that as point $C$ in design 1 goes up, design 2 goes down. This is caused by the position of the Z-axis EGSC yoke plate, which is not located at the midpoint of the baseplate. However, it is relatively close to the position of points $C, F$, and I. The safety factor results have reversed values, compared to the displacement and maximum stress, where the safety factor is becoming higher when the value displacement and maximum stress are getting smaller. The safety factor value in design 1 is better than that in design 2 at six critical points ( $A, B, C, G, H$, and I). Almost the same values are found at points $D, E$, and $F$.

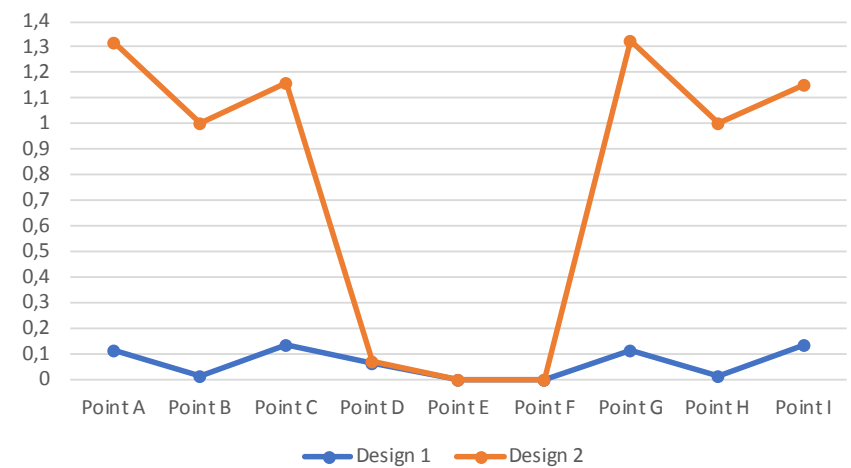

Figure 23: Comparison of displacement value of designs 1 and 2 
Table 6: FEM simulation result of the 9 point baseplates test

\begin{tabular}{|c|c|c|c|}
\hline Position & Parameter & Design 1 & Design 2 \\
\hline \multirow{3}{*}{ Point A } & Displacement (mm) & $1.13 \times 10^{-1}$ & 1.32 \\
\hline & Maximum tensile strength (MPa) & 59.15 & 191.91 \\
\hline & Safety factor & 11.37 & 7.89 \\
\hline \multirow{3}{*}{ Point B } & Displacement (mm) & $1.64 \times 10^{-2}$ & 1.001 \\
\hline & Maximum tensile strength (MPa) & 28.91 & 151.28 \\
\hline & Safety factor & 15 & 10.01 \\
\hline \multirow{3}{*}{ Point C } & Displacement (mm) & $1.37 \times 10^{-1}$ & 1.16 \\
\hline & Maximum tensile strength (MPa) & 60.74 & 143.951 \\
\hline & Safety factor & 10.68 & 9.27 \\
\hline \multirow{3}{*}{ Point D } & Displacement (mm) & $6.45 \times 10^{-2}$ & $7.16 \times 10^{-2}$ \\
\hline & Maximum tensile strength (MPa) & 35.29 & 40.73 \\
\hline & Safety factor & 13.88 & 13.84 \\
\hline \multirow{3}{*}{ Point E } & Displacement (mm) & $7.02 \times 10^{-4}$ & $7.02 \times 10^{-4}$ \\
\hline & Maximum tensile strength (MPa) & 8.54 & 8.54 \\
\hline & Safety factor & 15 & 15 \\
\hline \multirow{3}{*}{ Point F } & Displacement (mm) & $7.73 \times 10^{-4}$ & $7.78 \times 10^{-4}$ \\
\hline & Maximum tensile strength (MPa) & 8.75 & 9.19 \\
\hline & Safety factor & 15 & 15 \\
\hline \multirow{3}{*}{ Point G } & Displacement (mm) & $1.13 \times 10^{-1}$ & 1.325 \\
\hline & Maximum tensile strength (MPa) & 68.21 & 194.403 \\
\hline & Safety factor & 13.23 & 7.79 \\
\hline \multirow{3}{*}{ Point $\mathrm{H}$} & Displacement (mm) & $1.59 \times 10^{-2}$ & 1.001 \\
\hline & Maximum tensile strength (MPa) & 28.17 & 153.91 \\
\hline & Safety factor & 15 & 9.84 \\
\hline \multirow{3}{*}{ Point I } & Displacement (mm) & $1.39 \times 10^{-1}$ & 1.15 \\
\hline & Maximum tensile strength (MPa) & 68.45 & 142.32 \\
\hline & Safety factor & 12.82 & 10.64 \\
\hline
\end{tabular}

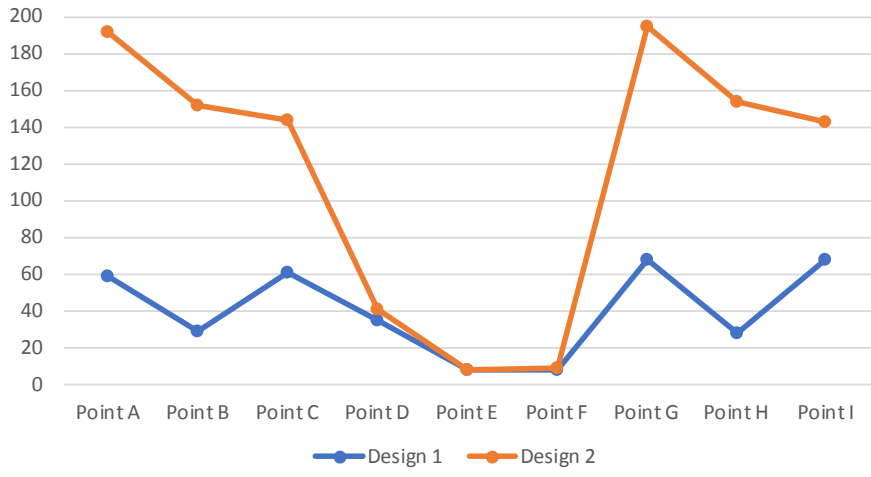

Figure 24: Comparison of the maximum stress value of designs 1 and 2

\section{CONCLUSIONS}

To recapitulate, the Auto Checking Hardness Machine has been successfully developed from the conventional form of the Mitutoyo Hardness Tester HR-522 into an automated machine with some advantages, such as an as-

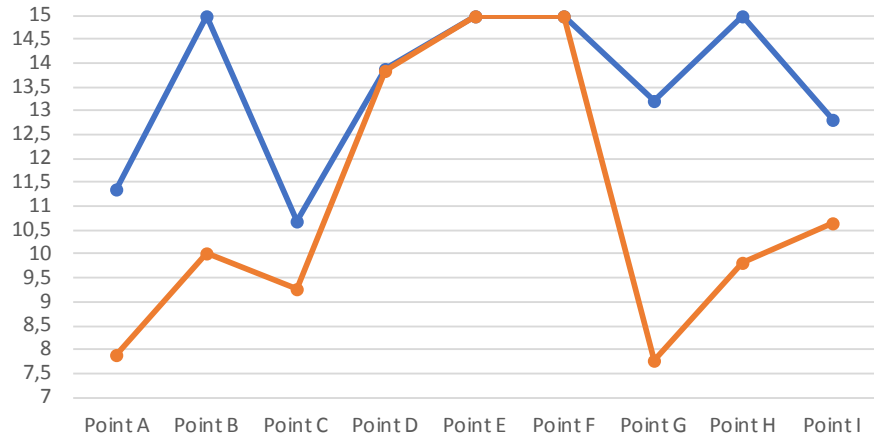

$$
\longrightarrow \text { Design } 1 \multimap \text { Design } 2
$$

Figure 25: Comparison of the safety factor of designs 1 and 2 sembled mechanism with a 3-axis linear drive, supported by a linear guide system. Moreover, this machine can be expected to significantly increase the time efficiency of production. First and foremost, the finite element simulation indicates that all four types of the aluminum frame can be used as the mainframe of automatic checking devices, as shown by the astonishing number achieved in 
this simulation. Nevertheless, the high-rigidity aluminum frame type obtained the best simulation score based on a low score of stress and displacement, with almost half of these values smaller than those of the three other types. On top of that, the high-rigidity frame type has the largest cross-sectional area and maximum tensile strength. Chiefly, an extensive cross-sectional area causes its moment of inertia to become more significant and its tensile strength to increase, thus indicating the essential properties of its elasticity modulus, which support its load resistance ability. Secondly, the baseplate simulation shows the performance of the linear guides, especially the Misumi linear guides, in resisting the checking loads from the indenter at all positions. In other words, the linear guides support the baseplate, particularly on the edge of the baseplate $(A, B, C, G, H$, and I). As illustrated in Figures 25 to 27, the resistance is about three times greater with the linear guides than without them.

\section{REFERENCES}

1. Fedyukov, V., Chernov, V., Chernova, M. (2020). Strength of aged wood in old constructions. Journal of Applied Engineering Science, vol. 18, no. 1, 114 119, DOI: https://doi.org/10.5937/jaes18-23002

2. Maljković, M., Blagojević, I., Popović, V., Stamenković, D. (2018). Impact of the damper characteristics on the behavior of suspension system and the whole vehicle. Journal of Applied Engineering Science, vol. 16, no. 3, 349-357, DOI: https://doi.org/10.5937/ jaes 16-17342

3. Prabowo, A.R., Bahatmaka, A., Sohn, J.M. (2020). Crashworthiness characteristic of longitudinal deck structures against identified accidental action in marine environment: a study case of ship-bow collision. Journal of the Brazilian Society of Mechanical Sciences and Engineering, vol. 42, no. 11, 584, DOl: https://doi.org/10.1007/s40430-020-02662-2

4. Sakuri, S., Surojo, E., Ariawan, D., Prabowo, A.R. (2020). Experimental investigation on mechanical characteristics of composite reinforced cantala fiber (CF) subjected to microcrystalline cellulose and fumigation treatments. Composites Communication, vol. 21, 100419, DOI: https://doi.org/10.1016/j. coco.2020.100419

5. Ariawan, D., Rivai, T.S., Surojo, E., Hidayatulloh, S., Akbar, H.I., Prabowo, A.R. (2020). Effect of alkali treatment of Salacca Zalacca fiber (SZF) on mechanical properties of HDPE composite reinforced with SZF. Alexandria Engineering Journal, vol. 59, no. 5, 3981-3989, DOI: https://doi.org/10.1016/j. aej.2020.07.005

6. Afridi, B.Z., Shahzadam K., Naqash, M.T. (2017). Mechanical properties of polypropylene fibers mixed cement-sand mortar. Journal of Applied Engineering Science, vol. 17, no. 2, 116 - 125, DOI: https://doi. org/10.5937/jaes17-19092
7. Prabowo, A.R., Cahyono, S.I., Sohn, J.M. (2019). Crashworthiness assessment of thin-walled double bottom tanker: A variety of ship grounding incidents. Theoretical and Applied Mechanics Letters, vol. 9, no. 5, 320-327, DOI: https://doi.org/10.1016/j. taml.2019.05.002

8. Guo, B., Zhang, L., Cao, L., Zhang, T., Jiang, F., Yan, L. (2018). The correction of temperature-dependent Vickers hardness of cemented carbide base on the developed high-temperature hardness tester. Journal of Materials Proceeding Technology, vol. 255, 426-433, DOI: https://doi.org/10.1016/j.jmatprotec.2017.12.041

9. Caesar, B.P.P., Hazimi, H., Sukanto, H., Prabowo, A.R. (2020). Development of novel design and frame structural assessment on Mitutoyo's Auto Checking Hardness Machine using reverse engineering approach: series HR-522 hardness tester. Journal of Engineering Science and Technology, vol. 15, no. 2, 1296-1318, DOI:

10. Batan, I.M.L. (2012). Desain Produk. 1st Edition, Guna Widya, Surabaya (in Indonesian).

11. Husain, Z., Jan, H. (2019). Establishing a simulation model for optimizing the efficiency of the CNC machine using a reliability-centered maintenance approach. International Journal of Modeling, Simulation, and Scientific Computing, vol. 10, no. 6, 1950034, DOI: https://doi.org/10.1142/S179396231950034X

12. TA Instruments. Automated Hardness Tester Brochure, from https://www.tainstruments.com/aht/, accessed on 2020-12-08.

13. Wang, W., Zhang, Y., Li, C. (2017). Dynamic reliability analysis of linear guides in positioning precision. Mechanism and Machine Theory, vol. 116, 451 464, DOI: https://doi.org/10.1016/j.mechmachtheory.2017.06.011

14. Hong, C.C., Chang, C.L., Lin, C.Y. (2016). Static structural analysis of great five-axis turning-milling complex CNC machine. Engineering Science and Technology, an International Journal, vol. 19, no. 4, 1971-1984, DOI: https://doi.org/10.1016/j. jestch.2016.07.013

15. Francoisa, P., Palit, A., Gerbino, S., Ceglarek, D. (2019). A novel hybrid shell element formulation (QUAD+ and TRIA+): A benchmarking and comparative study. Finite Elements in Analysis and Design, vol. 166, 103319, DOI: https://doi.org/10.1016/j.finel.2019.103319

16. Hidayat, T., Nazaruddin, N., Syafri S. (2017). Perancangan dan analisis statik chassis kendaraan shell eco marathon tipe urban concept. Jurnal Online Mahasiswa Fakultas Teknik Universitas Riau, vol. 4, no. 2, 1-6, DOI: - (in Indonesian). 
17. Prabowo, A.R., Putranto, T., Sohn, J.M. (2019). Simulation of the behavior of a ship hull under grounding: Effect of applied element size on structural crashworthiness. Journal of Marine Science and Engineering, vol. 7, no. 8, 270, DOI: https://doi. org/10.3390/jmse7080270

18. Kõrgesaar, M, (2015). Modeling ductile fracture in ship structures with shell element. Aalto University, Espoo.

19. Buldgen, L., Sourne, H.L., Besnard, N., Rigo, P. (2012). Extension of the super-elements method to the analysis of oblique collision between two ships. Marine Structures, vol. 29, no. 1, 22-57, DOI: https:// doi.org/10.1016/j.marstruc.2012.08.002

20. Lee, Y.W., Woertz, J.C., Wierzbicki, T. (2004). Fracture prediction of thin plates under hemi-spherical punch with calibration and experimental verification. International Journal of Mechanical Sciences, vol. 46, no. 5, 751-781, DOI: https://doi.org/10.1016/j. ijmecsci.2004.05.004

21. Simonsen, B.C., Lauridsen, L.P. (2000). Energy absorption and ductile failure in metal sheets under lateral indentation by a sphere. International Journal of Impact Engineering, vol. 24, no. 10, 1017-1039, DOI: https://doi.org/10.1016/S0734-743X(00)00024-5

22. Muttaqie, T., Thang D.Q., Prabowo, A.R., Cho, S.R., Sohn, J.M. (2019). Numerical studies of the failure modes of ring-stiffened cylinders under hydrostatic pressure. Structural Engineering and Mechanics,vol. 70, no. 4, 431-443, DOl: http://dx.doi.org/10.12989/ sem.2019.70.4.431

23. Misumi. MISUMI Automation Components, from https://us.misumi-ec.com/vona2/maker/misumi/ mech/, accessed on 2020-08-20.

24. El-Sammane, H., Ashry, A.H., Abou-leila, M., Arafa, W., Ahmad, U. (2012). A nuclear tester for micro-hardness measurement. Nuclear Instruments and Methods in Physics Research Section B: Beam Interactions with Materials and Atoms, vol. 290, 3942, DOI: https://doi.org/10.1016/j.nimb.2012.08.021

25. Beer, F.P., Johnston, E.R., Dewolf, J.T., Mazurek, D.F. (2012). Mechanics of Materials, 6th edition. McGraw-Hill, New York.

26. Dieter, G.E., Linda C.S. (2021). Engineering Design, 6th edition. McGraw-Hill, New York.

27. Caesar, B.P.P., Istanto, I., Pratama, P.S., Cho, J.H., Prabowo, A.R., (2020). Improvement of auto checking hardness machine using several material series of aluminum structural frame: Case study on mitutoyo hr-522 hardness tester. Procedia Structural Integrity, vol. 27, 117-124, DOI: https://doi.org/10.1016/j.prostr.2020.07.016

28. Wredenberg, F., Larsson, P. (2009). Scratch testing of metals and polymer: Experiments and numerics. Wear, vol. 266, no. 1-2, 76-83, DOI: https://doi. org/10.1016/j.wear.2008.05.014
29. Mutalib, A.A., Mussa, M.H., Abdulghafoor A.M. (2018). Finite element analysis of composite plate girders with a corrugated web. Journal of Engineering Science and Technology, vol. 13, no. 9, 29782994, DOI: -

30. Marjanović, M., Marković, N., Damnjanović, E., Cvetković, R. (2020). Three-dimensional stress analysis and design of cross-laminated timber panels using full-layerwise-theory-based finite element method. Thin-Walled Structures, vol. 157, 107156, DOI: https://doi.org/10.1016/j.tws.2020.107156

31. Castaldo, P., Gino, D., Bertagnoli, G., Mancini, G. (2018). Partial safety factor for resistance model uncertainties in 2D non-linear finite element analysis of reinforced concrete structures. Engineering Structures, vol. 176, 746-762, DOI: https://doi. org/10.1016/j.engstruct.2018.09.041

32. Kefal, A., Tessler, A., Oterkus, E. (2017). An enhanced inverse finite element method for displacement and stress monitoring of multilayered composite and sandwich structures. Composite Structures, vol. 179, 514-540, DOI: https://doi.org/10.1016/j. compstruct.2017.07.078

33. Prabowo, A.R., Bae, D.M., Cho, J.H., Sohn, J.M. (2017). Analysis of structural crashworthiness and estimating safety limit accounting for ship collisions on strait territory. Latin American Journal of Solids and Structures, vol. 14, no. 8, 1594-1613, DOI: http://dx.doi.org/10.1590/1679-78253942

34. Vogel, D., Wehmeyer, M., Kebbach, M., Heyer, H., Bader, R. (2021). Stress and strain distribution in femoral heads for hip resurfacing arthroplasty with different materials: A finite element analysis. Journal of the Mechanical Behavior of Biomedical Materials, vol. 113, 104115, DOI: https://doi.org/10.1016/j. jmbbm.2020.104115

Paper submitted: 10.12.2021.

Paper accepted: 01.03.2021.

This is an open access article distributed under the CC BY 4.0 terms and conditions.

Istraživanja i projektovanja za privredu ISSN 1451-4117 Journal of Applied Engineering Science Vol. 19, No. 3, 2021 